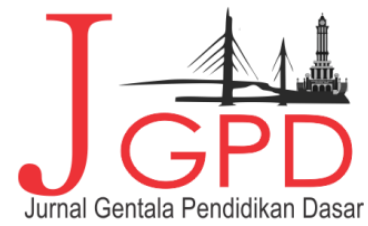

JURNAL GENTALA PENDIDIKAN DASAR Vol.4 № 2 December 2019 Page 201-208

P-ISSN : 2614-7092, E-ISSN : 2621-966II

Available Online at Web : http://anline-juurnal.unja.ac.id/index.php/gentala

email : penyunting.jurnal.g-pgsd国unja.ac.id

Research Article

\title{
Pengembangan Multimedia Interaktif Berbasis Unity Pada Subtema Keberagaman Budaya Bangsaku di Kelas IV Sekolah Dasar
}

\author{
Muhammad Sofwan, Moch Bayu Eko Wibowo
}

Program Studi Pendidikan Guru Sekolah Dasar, FKIP, Universitas Jambi, Jambi, Indonesia

\begin{tabular}{|c|c|}
\hline \multirow{5}{*}{$\begin{array}{l}\text { Article Information } \\
\text { Reviewed : Nov 17, } 2019 \\
\text { Revised : Nov 28, } 2019 \\
\text { Available Online : Dec 27, } 2019\end{array}$} & \multirow{7}{*}{$\begin{array}{l}\text { ABSTRACT } \\
\text { This research is a research development that aims to be able to } \\
\text { produce interactive multimedia products based on a valid and } \\
\text { practical unity. The results of the development were then tested } \\
\text { on SD N } 47 \text { / IV Jambi City in class IV.F with a total of } 30 \\
\text { students. This research was conducted at SD N } 47 \text { / IV Jambi } \\
\text { City. The research data were obtained by validating media } \\
\text { experts, validating learning experts, teacher questionnaires and } \\
\text { student questionnaires, which were strengthened by } \\
\text { documentation data. After the data is obtained, then a percentage } \\
\text { of the data is searched using a predetermined formula to see the } \\
\text { feasibility of the developed media. The types of data used in this } \\
\text { study are qualitative and quantitative data. Based on the results } \\
\text { of this study, teachers are expected to be able to develop a } \\
\text { technology-based media with the aim of creating enjoyable } \\
\text { learning and creating a new atmosphere in the classroom that } \\
\text { can be concluded that the development of Unity-Based } \\
\text { Interactive Multimedia in the Sub-theme of Cultural Diversity of } \\
\text { Banngsaku in Class IV Elementary Schools is included in the } \\
\text { category valid and practical. }\end{array}$} \\
\hline & \\
\hline & \\
\hline & \\
\hline & \\
\hline $\begin{array}{l}\text { Keyword } \\
\text { Pengembangan, } \\
\text { Interaktif, Unity }\end{array}$ & \\
\hline & \\
\hline
\end{tabular}

DOI : https://doi.org/10.22437/gentala.v4i2.8438

\section{PENDAHULUAN}

Perkembangan teknologi pada era modern telah memiliki perkembangan yang sangat pesat. Perkembangan teknologi telah memberikan dampak yang lebih baik pada era modern, baik dalam bidang komunikasi, transportasi, budaya, dan pendidikan. Dalam bidang pendidikan, pemanfaatan teknologi, informasi, dan komunikasi digunakan untuk meningkatkan efisiensi dan efektivitas dalam pembelajaran (Permendikbud 2016, No 22). Di jenjang pendidikan Sekolah Dasar, teknologi juga turut membantu guru menyampaikan materi kepada peserta didik terutama pada materi yang membutuhkan beberapa format media demi ketercapaian tujuan pembelajaran, seperti halnya pada Subtema Keberagaman Budaya Bangsaku.

Pada Kurikulum 2013 pada Subtema Keberagaman Budaya Bangsaku, Kompetensi Dasar 3.4 Mengindentifikasi berbagai bentuk keberagaman suku bangsa, sosial, dan budaya 


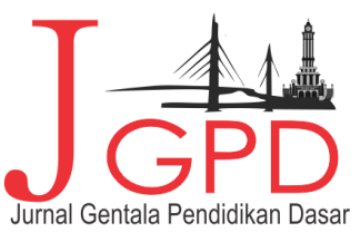

JURNAL GENTALA PENDIDIKAN DASAR Vol.4 № 2 December 2019 Page 201-208

P-ISSN : 2614-7092, E-ISSN : 2621-961I

Available Dnline at Web : http://online-juurnal.unja.ac.id/index.php/gentala email : penyunting.jurnal.g-pgsd国unja.ac.id

di Indonesia yang terikat persatuan dan kesatuan. Dalam menyampaikan informasi yang terkandung dalam materi yang diajarkan, dibutuhkan media pembelajaran yang mampu membantu peserta didik dalam memahami materi yang dipelajari. Penggunaan media pembelajaran dibutuhkan selain membantu peserta didik untuk memahami materi yang dipelajari juga untuk menjadikan pembelajaran jauh lebih optimal. Salah satu media yang mampu membantu siswa pada pembelajaran di kelas berupa Media berbasis teknologi informasi. Menurut Nurchaili (2010:649) Penerapan Teknologi Informasi di bidang pendidikan, khususnya dalam proses pembelajaran diyakini dapat memberikan pengaruh yang signifikan dalam meningkatkan kualitas pendidikan. Penggunaan teknologi juga mampu membuat peserta didik melakukan kontrol terhadap aktivitas belajarnya, selain itu teknologi juga mampu mengintegrasikan beberapa komponen yang dapat mendukung aktivitas pembelajaran.

Berdasarkan pengamatan yang dilakukan peneliti di SDN 47/IV Kota Jambi pada proses pembelajaran Subtema Keberagaman Budaya Bangsaku . Guru menggunakan buku cetak dan papan tulis sebagai media dalam pembelajaran. Penggunaan media berupa buku cetak dan papan tulis sebenarnya telah mampu menjadi alat perantara dalam menyampaikan informasi yang terkandung pada Subtema Keberagaman Budaya Bangsaku. Akan tetapi, penggunaan media berupa buku cetak dan papan tulis memiliki keterbatasan dalam konteks isi ataupun materi. Penggunaan media berupa buku cetak dan papan tulis memiliki kekurangan diantaranya berupa keterbatasan pembelajaran yang kontekstual bagi peserta didik, dikarenakan materi yang terdapat pada buku cetak hanya memuat mengenai kebudayaan daerah secara umum. Padahal penerapan pembelajaran yang kontekstual, mampu memberikan pembelajaran yang sesuai dengan situasi dunia nyata peserta didik (Suprijono:2009), sehingga memudahkan peserta didik dalam menerima pembelajaran yang diberikan oleh guru.

Berdasarkan permasalahan tersebut, maka dibutuhkan sebuah media yang mampu memberikan pembelajaran yang kontekstual bagi peserta didik. Salah satu media yang mampu mengatasi permasalahan dalam pembelajaran tersebut berupa penggunaan multimedia interaktif. Penggunaan multimedia interaktif dinyatakan sesuai dengan materi keberagaman budaya bangsaku dikarenakan multimedia interaktif mampu menggabungkan beberapa media menjadi satu kesatuan, selain itu dengan menggunakan multimedia interaktif 


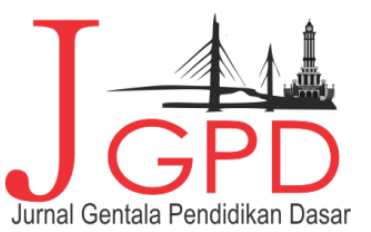

JURNAL geNTALA PENDIDIKAN DASAR Vol.4 No 2 December 2019 Page 201-208

P-ISSN : 2614-7092, E-ISSN : 2621-966II

Available Cnline at Web : http://online-journal.unja.ac.id/index.php/gentala email : penyunting.jurnal.g-pgsd国unja.ac.id

guru mampu mengembangkan pembelajaran yang kontekstual serta menyajikan informasi yang dapat dilihat, didengar dan dilakukan sekaligus, sehingga memungkinkan peserta didik untuk mengingat materi yang diajarkan secara maksimal.

Dalam mengembangkan multimedia interaktif pada proses pembelajaran, dapat dilakukan dengan berbagai macam aplikasi. Salah satu aplikasi yang mampu mengembangkan multimedia interaktif yang menarik dalam proses pembelajaran adalah unity. Dengan menggunakan unity, pengembang mampu berkreatifitas dalam menghasilkan produk berupa multimedia interaktif, karena sesuai fungsinya unity digunakan untuk membuat berbagai macam konsol atau perangkat bergerak (Faiztyan: 2015).

Berdasarkan pemaparan tersebut, peneliti tertarik untuk melakukan penelitian yang berjudul "Pengembangan Multimedia Interaktif berbasis Unity pada Subtema Keberagaman Budaya Bangsaku di kelas IV Sekolah Dasar"

\section{METODE PENELITIAN DAN PENGEMBANGAN}

Penelitian ini menggunakan metode kualitatif dan kuantitatif, metode ini berlandaskan pada beberapa fenomena yang terjadi pada pembelajaran di SD. Model pengembangan yang digunakan dalam penelitian ini adalah model ADDIE, yang mana tahap pertama adalah melakukan analisis, analisis yang dilakukan dalam penelitian ini meliputi analisis kurikulum, analisis karakteristik peserta didik, dan analisis kubutuhan peserta didik. Tahap kedua yaitu design, pada tahap ini adapun kegiatan yang dilaksanakan meliputi pembuatan instrument penilaian, menentukan KI, KD, Indikator, serta tujuan pembelajaran yang digunakan, membuat list barang dan merancang RPP. Tahap yang ketiga yaitu pengembangan produk, dalam pengembangan produk kegiatan yang dilaksanakan adalah menyiapkan konten beserta menggabungkannya dan melakukan validasi ahli media dan pembelajaran. Tahap keempat yaitu implementasi produk di sekolah, implementasi ini dilakukan untuk mengetahui kepraktisan dari produk yang dikembangkan melalui hasil penilaian angket yang diberikan oleh guru dan peserta didik. Tahap terakhir yaitu evaluasi, dalam model pengembangan ADDIE evaluasi dilakukan pada tiap tahapan.

\section{HASIL PENELITIAN DAN PEMBAHASAN}

\section{Hasil Penelitian}




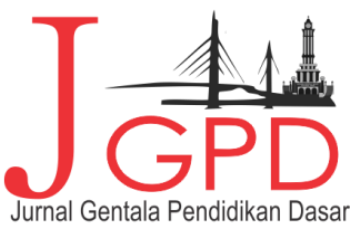

JURNAL GeNTALA PENDIDIKAN DASAR Vol.4 № 2 December 2019 Page 20I-208

P-ISSN : 2614-7092, E-ISSN : 2621-966II

Available Online at Web : http://online-journal.unja.ac.id/index.php/gentala

email : penyunting.jurnal.q-pgsd国unja.ac.id

Berdasarkan hasil angket yang didapatkan dari validator ahli media dan pembelajaran serta angket guru dan peserta didik. Didapatkanlah hasil sebagai berikut.

Evaluasi oleh ahli media pada tahap I mendapatkan rata rata nilai dengan persentase sebesar 52\% yang termasuk dalam kategori "sangat tidak valid" maka dari itu peneliti melakukan revisi sesuai saran yang diberikan oleh validator ahli media. Pada validasi kedua mendapat rata rata nilai dengan persentase sebesar $98 \%$ yang termasuk dalam kategori "sangat valid".

Evaluasi oleh ahli pembelajaran pada tahap I mendapatkan rata nilai dengan persentase sebesar 73\% yang termasuk dalam kategori "kurang valid" maka dari itu peneliti melakukan revisi sesuai saran yang diberikan oleh validator ahli pembelajaran. Pada validasi kedua mendapatkan rata rata nilai dengan persentase sebesar $81 \%$ yang termasuk dalam kategori "valid".

Tahapan selanjutnya adalah menguji cobakan produk yang telah divalidasi, untuk melihat tingkat kepraktisan dari produk yang dikembangkan. Berdasarkan hasil penilaian angket yang diberikan oleh guru dan peserta didik, produk yang dikembangkan mendapatkan tanggapan yang positif. Hasil penilaian angket kepraktisan yang diberikan oleh guru mendapatkan nilai dengan persentase sebesar $98 \%$ yang termasuk dalam kategori "sangat praktis". Hasil penilaian angket kepraktisan selanjutnya diberikan oleh seluruh peserta didik kelas IV.F dengan persentase nilai sebesar $87 \%$ yang termasuk dalam kategori "praktis". Hal ini memberikan arti bahwa media yang dikembangkan layak untuk membantu peserta didik dalam mengenalkan kebudayaan daerah pada tiap kabupaten di Provinsi Jambi.

\section{Pembahasan}

Penelitian ini merupakan jenis penelitian pengembangan (research and development). Penelitian ini menggunakan model pengembangan ADDIE untuk mengembangakan produk penelitian. Pemilihan model pengembangan ADDIE dikarenakan model pengembangan ini mudah untuk dipelajari dan memiliki langkah langkah yang lebih sistematis dan tepat untuk media berbasis multimedia. 


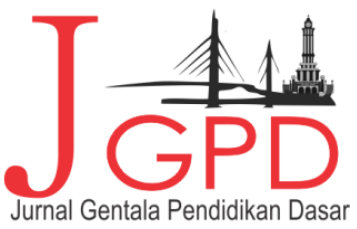

JURNAL GeNTALA PENDIDIKAN DASAR Vol.4 № 2 December 2019 Page 20I-208

P-ISSN : 2614-7092, E-ISSN : 2621-961I

Available Cnline at Web : http://online-juurnal.unja.ac.id/index.php/gentala email : penyunting.jurnal.g-pgsd国unja.ac.id

Langkah langkah dalam model pengembangan ADDIE terdiri atas beberapa tahapan, yaitu analisis, desain, pengembangan, implementasi, dan evaluasi pada seluruh tahapan jika diperlukan. Tahapan pertama yaitu analisis. Tahap ini didasarkan pada analisis kurikulum 2013, analisis karakteristik peserta didik, dan analisis kebutuhan. Tahapan kedua yaitu design, pada tahap ini hal yang pertama peneliti lakukan adalah pembuatan instrumen penilaian untuk ahli media, ahli pembelajaran, angket guru, dan angket siswa. Selanjutnya peneliti menentukan $\mathrm{KI}, \mathrm{KD}$, indikator, dan tujuan pembelajaran dilanjutkan dengan membuat RPP untuk uji coba kelompok besar. Sebelum mengembangkan produk peneliti terlebih dahulu mengumpulkan alat dan bahan untuk mengembangkan multimedia interaktif, alat dan bahan yang dikumpulkan seperti, komputer, aplikasi unity, aplikasi photosop, aplikasi pengubah suara, dan konten isi media yang didapat dari internet ataupun dikembangkan sendiri oleh peneliti. Tahap ketiga adalah pengembangan, tahap ini merupakan tahap dalam mengembangkan produk penelitian dengan alat dan bahan yang telah dikumpulkan sebelumnya. Pada tahap ini juga dilakukan validasi oleh validator ahli media dan validator ahli pembelajaran untuk mengetahui kekurangan dari produk yang dikembangkan serta direvisi sesuai saran dari validator. Pada validasi ahli media terdapat 10 butir tanggapan yang harus diberikan oleh validator ahli media. Sementara pada validasi ahli pembelajaran terdapat 17 butir tanggapan yang harus diberikan oleh validator ahli pembelajaran. Hasil validasi pada tahap akhir dari validator ahli media memperoleh penilaian dengan kategori "sangat valid". Lalu hasil validasi pada tahap akhir dari validator ahli pembelajaran memperoleh penilaian dengan kategori "valid".

Data dalam penelitian ini didapatkan dari validator ahli media, validator ahli pembelajaran, guru dan siswa. Angket dalam peneltian pengembangan ini menggunaakan pernyataan positif (skala likert) menurut sukardi (2009:146) dengan skor yang diberikan yaitu, 1 (sangat kurang sesuai), 2 (kurang sesuai), 3 (cukup sesuai), 4 (sesuia), serta 5 (sangat sesuai). Setelah penilaian diberikan, langkah selanjutnya adalah menghitung penilaian yang didapatkan menggunakan rumus yang telah ditentukan, hasil yang didapatkan menjadi dasar untuk melihat kualifikasi produk yang dinilai.

Setelah produk dinyatakan layak diuji cobakan oleh validator ahli media dan ahli pembelajaran, tahapan berikutnya yaitu implementasi. Menurut Asyhar (2012) salah satu kriteria media dikatakan baik yaitu media tersebut haruslah praktis, luwes, dan tahan. Tahap 


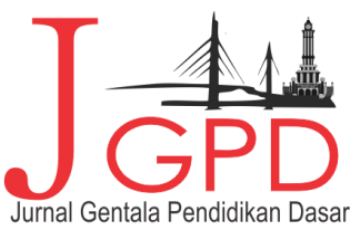

JURNAL GeNTALA PENDIDIKAN DASAR Vol.4 № 2 December 2019 Page 201-208

P-ISSN : 2614-7092, E-ISSN : 2621-961I

Available Online at Web : http://online-journal.unja.ac.id/index.php/gentala

email : penyunting.jurnal.g-pgsd国unja.ac.id

implementasi dilakukan untuk mengetahui tingkat kepraktisan dari produk yang dikembangkan, dengan melihat hasil penilaian yang diberikan oleh subjek uji coba dalam penelitian ini yaitu guru dan peserta didik kelas IV. F SDN 47/IV Kota Jambi.

Pada penelitian ini tahap implementasi terhadap produk yang dikembangkan terdiri atas 2 tahap uji coba yaitu uji coba kelompok kecil dan uji coba kelompok besar. Subjek uji coba kelompok kecil terdiri atas 6 peserta didik yang dipilih secara heterogen dengan berkonsultasi pada guru kelas. Subjek uji coba kelompok besar dilakukan pada seluruh peserta didik kelas IV.F. Hasil yang didapatkan dari uji coba kelompok kecil berupa respon dan saran terhadap produk yang dikembangkan serta menjadi dasar untuk merevisi produk yang dikembangkan sebelum diuji cobakan dalam kelompok besar. Respon peserta didik terhadap produk yang dikembangkan adalah dapat digunakan dengan baik dan mudah digunakan oleh peserta didik. Pada uji coba kelompok besar hasil yang didapatkan berupa angket penilaian dari guru kelas dan seluruh peserta didik kelas IV.F. Hasil penilaian angket oleh guru dan peserta didik menujukkan bahwa produk yang dikembangkan memiliki dampak positif terhadap proses pembelajaran. Proses pembelajaran yang dimaksud adalah pembelajaran yang hanya memuat materi tentang PPKn.

Berdasarkan hasil uji coba tersebut, maka dapat disimpulkan bahwasanya multimedia interaktif berbasis unity memiliki tingkat validitas dengan sangat valid serta mampu membantu peserta didik dalam memahami keberagaman budaya di Provinsi Jambi, berupa informasi daerah, pakaian adat, rumah adat, makanan khas, serta lagu daerah yang terdapat di Provinsi Jambi, selain itu juga terdapat kuis dan puzzle sebagai permainan yang membantu peserta didik agar mampu memperkuat materi mengenai keberagaman budaya di Provinsi Jambi.

\section{KESIMPULAN DAN IMPLIKASI}

\section{Kesimpulan}

Berdasarkan hasil penelitian dan pengembangan multimedia interaktif penelitian ini menggunakan model pengembangan tipe ADDIE, dengan tingkat kevalidan produk sebesar 98\% oleh validator ahli media dan $81 \%$ oleh validator ahli pembelajaran. 


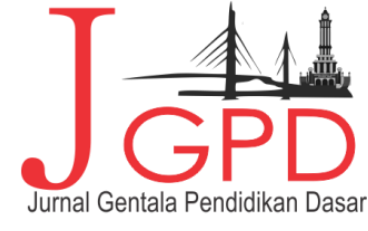

Implikasi
JURRAL gENTALA PENDIDIKAN DASAR Vol.4 No 2 December 2019 Page 201-208

P-ISSN : 2614-7092, E-ISSN : 2621-9611

Available Dnline at Web : http://online-journal.unja.ac.id/index.php/gentala

email : penyunting.jurnal.g-pgsd国unja.ac.id

Berdasarkan hasil penelitian, implikasi skripsi ini adalah sebagai berikut:

1. Multimedia interaktif berbasis unity pada materi Keberagaman Budaya mampu memberikan pembelajaran yang kontekstual bagi peserta didik.

2. Multimedia interaktif berbasis unity mampu membantu peserta didik dalam mencapai KD 3.4 Mengidentifikasi berbagai bentuk keberagaman suku bangsa, sosial, dan budaya di Indonesia yang terikat persatuan dan kesatuan KD 4.4 Menyajikan berbagai bentuk keberagaman suku bangsa, sosial, dan budaya di Indonesia yang terikat persatuan dan kesatuan.

\section{Saran}

1. Dalam menerapkan produk yang dikembangkan, dibutuhkan beberapa komputer disesuaikan dengan jumlah peserta didik, agar pembelajaran dapat dilaksanakan.

2. Dalam proses pembelajaran diharapkan penelitian selanjutnya mampu mengatur alokasi waktu dengan baik dan telah menyiapkan produk yang dikembangkan sebelum pembelajaran dilaksanakan.

3. Peneliti menyarankan untuk penelitian selanjutnya agar mampu memberikan lebih banyak informasi mengenai keberagaman budaya di Provinsi Jambi dengan media yang lebih inovatif dan menarik.

\section{DAFTAR PUSTAKA}

Anitah, Sri. 2008. Media Pembelajaran. Surakarta: UNS Press.

Arsyad, Azhar. 1997. Media Pembelajaran. Jakarta: PT. Rajagrafindo Persada.

Asyhar, Rayandra. 2012. Kreatif Mengembangkan Media Pembelajaran. Jakarta: IKAPI

Emzir. 2015. Metodologi Penelitian Pendidikan. Jakarta: PT. Rajagrafindo Persada.

Faiztyan, Irham. 2015. Perancangan dan Pembuatan Aplikasi Visualisasi 3D Interaktif Masjid Agung Jawa Tengah Menggunakan Unity 3D. JTsiskom, 3(2), 208.

Hadi, Sutrisno. 2015. Metodologi Riset. Yogyakarta: Pustaka Belajar.

Hanggoro, Adhiim Catur. 2015. Pembuatan Aplikasi Permainan "Jakarta Bersih" Berbasis Unity. JTsiskom, 3(4), 504. 


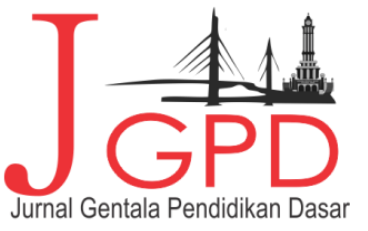

JURNAL geNTALA PENDIDIKAN DASAR Vol.4 No 2 December 2019 Page 201-208 P-ISSN : 2614-7092, E-ISSN : 2621-966II

Available Dnline at Web : http://anline-journal.unja.ac.id/index.php/gentala email : penyunting.jurnal.q-pgsd国unja.ac.id

Haryati, Sri. 2012. Research and Development Sebagai Salah Satu Model Penelitian Dalam Bidang Pendidikan.UTM, 37(1), 13-14.

Kurniawan, A. R. (2016). Pengembangan Perangkat Pembelajaran IPA berbasis Pendekatan

Penemuan Terbimbing untuk Melatihkan Keterampilan Proses Siswa Sekolah

Dasar. Jurnal Review Pendidikan Dasar: Jurnal Kajian Pendidikan Dan Hasil Penelitian, 2(2), 175-183.

Mahnun, Nunu. 2012. Media Pembelajaran. UIN Suska Riau, 37(1), 28.

Munir. 2015. Multimedia Konsep dan Aplikasi dalam Pendidikan. Bandung: Alfabeta.

Nurchaili. 2010. Pengaruh Media Pembelajaran Berbasis Teknologi Informasi Dalam Proses

Pembelajaran Kimia Terhadap Peningkatan Hasil Belajar Siswa. Darussalam Kab. Aceh, 16(6), 650.

Putri, Inggrid Ayu. 2016. Pengembangan Media Pembelajaran Fisika Menggunakan Lectora Inspire pada Materi Usaha dan Energi SMA. Jurnal Penelitian dan Pengembangan Pendidikan Fisika, 2(2), 72.

Reddi, U.V. 2003. Multimedia as an educational tool. In educational multimedia: A handbook for teacher-developers. New Delhi: CEMCA

Roedavan, Rickman. 2016. Unity Tutorial Game Engine. Bandung: Informatika.

Suparno: 2002. Keterampilan Dasar Menulis. Jakarta: Universitas Terbuka, Departemen Pendidikan Nasional.

Suyanto, Muhammad. 2001. Multimedia Alat Untuk Meningkatkan Keunggulan Bersaing. Yogyakarta: Andi.

Suprijono, Agus. 2009. Cooperative Learning:Teori dan Aplikasi PAIKEM. Surabaya: Pustaka Pelajar.

Tegeh, I Made, dkk. 2014. Model Penelitian Pengembangan. Yogyakarta: Graha Ilmu.

Trianingsih, Rima. 2016. Pengantar Praktik Mendidik Anak Usia Sekolah Dasar. Al Ibtida, 3(2), 199.

Tung, Khoe Yao. 2017. Desain Intruksional.Yogyakarta: CV. ANDI OFFSET. 